\title{
Programas habitacionales, estrategias residenciales y modos de vida. La construcción de territorios 'inapropiados' en la ciudad de Santa Fe
}

\section{Housing programs, residential strategies and ways of life. The construction of 'inappropriate' territories in the city of Santa Fe}

Martín Carné

Doctor en Ciencia Política. Investigador Asistente del Consejo Nacional de Investigaciones Científicas y Técnicas (CONICET). Instituto de Humanidades y Ciencias Sociales del Litoral. Universidad Nacional del Litoral (UNL-CONICET). Ciudad Universitaria. Paraje El Pozo, (3000) Ciudad de Santa Fe, Santa Fe, Argentina, carnetes@hotmail.com, ORCID https://orcid.org/0000-0003-2386-324X

Recibido: 5 de febrero 2020 || Aprobado: 4 de mayo 2020

Resumen

A partir de 2012, el Estado nacional y el de la provincia de Santa Fe implementaron programas de crédito para la construcción de vivienda y para la urbanización de suelo que expandieron la trama urbana, acentuando problemáticas típicas de 'ciudades difusas': áreas residenciales monofuncionales, mayores distancias de desplazamientos, déficits de equipamiento colectivo, entre otras. En base a entrevistas semiestructuradas a jefes/as de hogar del barrio Nueva Esperanza Este de la ciudad de Santa $\mathrm{Fe}$, se analizan las estrategias residenciales de hogares de sectores sociales medios, sus cambios en los modos de vida asociados a la nueva localización y el territorio que así construyen. Los resultados informan que la propiedad de la vivienda es priorizada a su localización y subordina las prácticas (familiares, laborales, recreativas) cotidianas, configurándose modos de vida más exigentes. Estos y la presencia cercana de grupos sociales percibidos como 'amenazantes', construyen un territorio 'inapropiado': parcialmente apropiado, usado, controlado.

Palabras clave: Programas habitacionales; Estrategias residenciales; Modos de vida; Territorios 'inapropiados'

\section{Abstract}

Since 2012, the national state and the province of Santa Fe implemented housing construction and land development programs that expanded the urban plot, accentuating typical problems of 'diffuse cities': monofunctional residential areas, greater distances of displacements, deficits of collective equipment, among others. Based on semi-structured interviews with heads of household of the Nueva Esperanza Este neighborhood of the city of Santa Fe, the research analyzes the residential strategies of middle-income household, their changes in the ways of life associated with the new location and the territory builded. The results inform that access to the property of the house is more valuable than its location and subordinates the daily practices (familiar, labor, recreational), configuring new and more demanding ways of life. These and the close presence of social groups perceived as 'threatening', build an 'inappropriate' territory: one partially appropriate, used, controlled.

Key words: Housing programs; Residential strategies; Ways of life; 'Inappropriate' territories

Cita sugerida: Carné, M. (2020). Programas habitacionales, estrategias residenciales y modos de vida. La construcción de territorios 'inapropiados' en la ciudad de Santa Fe. Estudios Socioterritoriales. Revista de Geografía, (28), 053. DOI: https://doi.org/10.37838/ unicen/est.28-053 


\section{INTRODUCCIÓN}

Dos manifestaciones de lo que de modo genérico podría denominarse 'cuestión urbana' refieren a la escasez de suelo servido (y su consecuente encarecimiento) y a las dificultades de buena parte de la población para llegar a la propiedad de la vivienda. En Argentina, en años recientes ${ }^{1}$, el Estado nacional y algunos estados provinciales buscaron mitigar estas falencias implementando programas de crédito -a tasa diferencial- para la construcción de vivienda y para la compra de lotes en suelo que urbanizaron previamente. Estas intervenciones, sin embargo, pueden acentuar algunas problemáticas típicas de 'ciudades difusas' (Dematteis, 1998). Así, la expansión horizontal de la trama urbana a la que contribuye este accionar estatal supone, para la población alcanzada por tales programas, nuevos y permanentes vínculos de vecindad con desconocidos, mayores distancias de desplazamiento (a lugares de trabajo, educación, consumo, esparcimiento), déficits en el transporte público de pasajeros, reducida provisión de equipamiento colectivo (plazas, parques, dispensarios, escuelas) y de comercios y servicios (personal para tareas domésticas y del cuidado). Vinculados con las áreas residenciales monofuncionales, estos cambios en las prácticas, rutinas y cotidianeidad de la población que se relocaliza pueden, eventualmente, afectar $y /$ o reorientar su sociabilidad y politicidad o, en otras palabras, el tipo y la frecuencia de contactos con sus redes sociales primarias y secundarias. En definitiva, programas estatales de esta naturaleza, queriendo mejorar las condiciones habitacionales de la población, podrían promover, como colateralidad, una disociación entre urbs y civitas (Ribeiro, 2007), un hiato entre la forma espacial poco compacta que le imprimen a la ciudad al querer ordenarla y el tipo de interacción social al que predisponen las prácticas cotidianas de los actores en el marco de dicha forma espacial. Este ángulo de las políticas habitacionales ha sido problematizado, en oportunidades, en referencia a experiencias de autoconstrucción en asentamientos irregulares o a programas estatales de construcción de barrios de vivienda social que involucran a población de sectores sociales bajos y/o medios-bajos, asumiendo con frecuencia que expresan formas de segregación socio-residencial (Elorza, 2019). No obstante, son escasos los trabajos que profundicen en las operaciones estatales de crédito hipotecario y urbanización y venta de suelo dirigidas a sectores sociales medios ${ }^{2}$ y/o medios-altos (Barenboim, 2018; Canestraro, 2016; Rodríguez, Di Virgilio, Arqueros Mejica, Rodríguez y Zapata, 2015). La localización de estos en áreas periféricas de la ciudad, distantes de las centralidades establecidas, ¿es necesariamente vivida como confinamiento? Los ajustes en los hábitos de ocio y consumo, ¿son tramitados con malestar o, por el contrario, han habilitado prácticas mejor ponderadas? ¿La propiedad es un valor al que se subordinan otras variables relacionadas? ¿Qué territorio se construye en estos procesos?

Dado lo expuesto, en base a una metodología cualitativa, el objetivo de la presente pesquisa es dar cuenta de las decisiones residenciales, los cambios en los modos de vida y el territorio construido por un grupo de hogares del barrio Nueva Esperanza Este

1 El análisis se centra en un programa aplicado entre 2012 y 2015 por el Estado nacional y en otro aplicado entre 2012 y 2019 por el Estado de la provincia de Santa Fe.

2 Se considera sectores medios a "una agrupación heterogénea que incluye asalariados (privados o estatales), profesionales, pequeños propietarios económicos (comerciales o artesanales), etc. Se diferencian 'hacia abajo' porque tienen capacidad monetaria de consumo mercantil y 'hacia arriba' porque no tienen capacidad de acumulación económica. Con esa noción tan amplia, quedan incluidas la clase media tradicional y la clase media alta" (Pírez, 2016, p. 295). 
del noreste de la ciudad de Santa $\mathrm{Fe}^{3}$ que edificó sus viviendas con recursos del Programa de Crédito Argentino del Bicentenario para la Vivienda Única Familiar (Pro.Cre.Ar, instrumentado por el Estado nacional en 2012) en lotes urbanizados en el marco del programa Mi Tierra, Mi Casa (MTMC) lanzado por el Estado de la provincia de Santa Fe en diciembre del mismo año. En efecto, el trabajo propone tanto ahondar en: a) los motivos y valores que, desde la óptica de los/as entrevistados/as, justifican su traslado a Nueva Esperanza Este; y b) los hábitos y prácticas cotidianas asociados a este traslado y en el tipo de producción territorial al que ellas dan lugar.

En términos teóricos, se sigue por un lado la perspectiva de las estrategias residenciales, según la cual los hogares guardan, al menos, un mínimo de libertad de acción para decidir sobre sus prácticas residenciales. Sin obviar que elecciones de esta naturaleza suelen estar constreñidas por diversos factores (situación ocupacional, nivel de ingresos, características del mercado inmobiliario, por ejemplo), el enfoque destaca que el modo de tenencia de la vivienda (propiedad o alquiler), el tipo de hábitat (casa o departamento) y su localización son variables decisivas que ayudan a explicar la realidad habitacional de los hogares. Por otro, se toman elementos de la sociología de la vida cotidiana para describir los modos de vida que se conforman en estos territorios que el Estado deliberadamente contribuye a configurar, modos de vida que, a su vez, moldean esos mismos territorios. Este recurso conceptual visibiliza la vida práctica de personas y/o grupos sociales para así informar acerca de la construcción del territorio que realizan. Se trata de una mirada que analiza la complejidad urbana partiendo de la palabra de los propios actores, quienes, con sus prácticas cotidianas y los significados que le atribuyen, hacen a un determinado tipo de territorio.

Las técnicas utilizadas para la producción de los datos son entrevistas semiestructuradas a jefas y jefes de hogar (unidades de observación) y análisis documental (normativa y documentos oficiales de divulgación). Gracias a los contactos de un primer informante del barrio, a modo de 'bola nieve' se fueron recolectando (entre los meses de octubre de 2019 y enero de 2020) los sucesivos testimonios de la muestra buscando respetar diferencias en cuanto a sexo, categoría ocupacional, composición del hogar y trayectoria residencial ${ }^{5}$. El uso de esta técnica responde, por un lado, al interés por "acceder a la perspectiva de los actores, para conocer cómo ellos interpretan sus experiencias en sus propios términos" (Marradi, Archenti y Piovani, 2007, p. 220); por otro, al carácter iniciático de la investigación, el cual la hace pertinente para identificar distintas dimensiones constitutivas del fenómeno.

El documento sigue la siguiente estructura. Luego de la introducción, se desarrolla el marco teórico que encuadra la investigación. Posteriormente se caracterizan los

3 Santa Fe es la ciudad capital de la provincia homónima. Según datos del último Censo Nacional de Población, Hogares y Viviendas realizado en 2010, contaba por entonces con 391.231 habitantes (Municipalidad de la Ciudad de Santa Fe y Bolsa de Comercio de Santa Fe, 2012). Ella es la principal sede de la administración pública del Estado provincial y presta además servicios logísticos, comerciales, de educación superior y de salud para buena parte de la población del centro-norte de la provincia.

4 En muchos casos, residentes de Nueva Esperanza Este desde 2015.

5 Las entrevistas fueron realizadas procurando respetar una guía de temas a abordar tales como trayectoria laboral, estrategias residenciales previas a la localización en Nueva Esperanza Este (ahorro para la compra de terreno/construcción, postulación a créditos hipotecarios en bancos públicos y/o privados, tenencia de planes de capitalización inmobiliaria), presencia de familiares en cercanías del barrio de destino como elemento condicionante de la decisión de localización, cambios en rutinas/prácticas cotidianas y en el tipo y frecuencia de encuentros sociales, vinculaciones con los vecinos e imágenes/representaciones del barrio. 
programas de los Estados nacional y provincial bajo los cuales los/las entrevistados/as accedieron al lote con servicios en el que construyeron su vivienda, así como también se presentan algunos rasgos del barrio Nueva Esperanza Este. A continuación, se pasa a la presentación y análisis de la evidencia producida para, por último, reflexionar sobre los resultados obtenidos y lo que informan sobre los territorios 'inapropiados' que se construyen en la periferia urbana.

\section{EL MARCO DE ANÁLISIS}

En sociedades capitalistas, aun cuando la vivienda es tratada como un bien mercantilizado, no todos los hogares acceden necesariamente a ella por medio de mecanismos de mercado. En su procura, ellos despliegan estrategias residenciales y movilizan recursos para resolver sus necesidades habitacionales dado que guardan "un mínimo de libertad de acción y de lucidez en sus prácticas residenciales" (Bonvalet y Dureau, 2002, p. 69) ${ }^{6}$. Dichas estrategias se definen como las decisiones y/o elecciones que los hogares siguen en materia de residencia. El rol del Estado en política habitacional, la situación ocupacional y de ingresos, la oferta de viviendas y el estado de la relación de fuerzas entre clases sociales son algunas de las variables que contribuyen a estructurar las opciones residenciales disponibles (Gutiérrez, 1995). Ante estas opciones, la implantación territorial de los hogares surge de la ponderación que realicen en cuanto a: a) el modo de ocupación de la vivienda (o régimen de tenencia), esto es, básicamente, si se la alquila o si se es su propietario/a; b) el tipo de hábitat -ya sea que se trate de una casa individual o de un departamento de propiedad horizontal-; y c) la localización de la vivienda (Bonvalet y Dureau, 2002). En su gran mayoría, los hogares deben priorizar alguna de estas variables y resignar las restantes.

En lo que refiere al régimen de tenencia, la propiedad de la vivienda es un hecho que, generalmente, indica estatus y ascenso social; el punto de llegada de la trayectoria residencial. En palabras de aquellos mismos autores, "la seguridad brindada por la propiedad inmobiliaria sustituye cada vez con mayor frecuencia la seguridad que ya no puede ofrecer el trabajo a muchos citadinos" (Bonvalet y Dureau, 2002, p. 75). Para sectores sociales medios y bajos, esta variable se antepone a la localización y al tipo de hábitat, de vivienda. En la otra mano, el alquiler/arrendamiento suele ser la opción más conveniente para hogares con relativa estabilidad laboral que priorizan la centralidad y el acceso a las infraestructuras y equipamientos colectivos aun cuando puedan tener que relocalizarse con mayor asiduidad. En cuanto al tipo de hábitat o vivienda, la casa individual -antes que el departamento en propiedad horizontal- es el ideal deseado (Bonvalet y Dureau, 2002). Ella es más común en ciudades -como las latinoamericanas- que tienden a expandirse hacia los bordes antes que en ciudades con crecimiento vertical. Es, además, versátil en tanto permite -eventualmente- montar un taller y/o una actividad comercial, ser ampliada para nuevos miembros del hogar, ofrecer en alquiler una habitación, por ejemplo. Ella también facilita cierto distanciamiento físico de los vecinos.

A su turno, como destacan los autores franceses ya citados, las decisiones relativas a la localización de la vivienda se vinculan con numerosos aspectos que hacen a lo que podría denominarse 'morfología urbana', esto es, la escala de la ciudad, la existencia

6 Acordando con lo apuntado por Di Virgilio y Gil y de Anso (2012), que a los hogares se les reconozca capacidad de agencia no implica adscribir al enfoque de la acción racional. 
de grupos sociales segregados, la distribución de las viviendas en relación con la distribución de los puestos de trabajo, de los espacios verdes, de las infraestructuras, de las áreas comerciales, entre otros. Aquí tallan aspectos tales como la cercanía al lugar de trabajo, la dotación de establecimientos educativos, comerciales, de salud, de ocio y/o esparcimiento; también importa el conocimiento que se tenga del lugar o las relaciones establecidas con sus habitantes (por el hecho de haber vivido allí, por ejemplo). Mientras en algunas ciudades el centro es elegido por familias acomodadas y/o por inmigrantes recientes (que encuentran alojamiento en edificios degradados) priorizando, en ambos casos, la cercanía al lugar de trabajo, en las periferias de otras ciudades se ubican hogares que desean hacerlo (con movilidad propia, que valoran la disponibilidad de mayor espacio, del contacto con la naturaleza, la idea de seguridad asociada a los barrios cerrados, etcétera) y hogares que desearían no hacerlo, pero voluntariamente lo hacen -a riesgo de cierto confinamiento y aceptando los costos del alejamiento-, priorizando la propiedad del lote y/o vivienda o bien la de autoconstruir (aun en zonas carentes de infraestructura, por ejemplo).

Las decisiones que toma un hogar a partir de las variables expuestas guardan relación con el modo de vida que desarrollen sus integrantes en el territorio. Este concepto designa el conjunto de "prácticas actuales, representaciones y creencias heredadas del pasado y proyectos y estrategias elaboradas para superar las condiciones de vida actuales; es decir, prácticas y proyectos orientados hacia el futuro" (Lindón, 2002, p. 35). Da visibilidad al hacer de las personas; "expresa los aspectos fenoménicos de cuestiones cognoscitivas (como representaciones, imágenes y categorías utilizadas por los individuos), cuestiones normativas (como valores, ethos, esperanzas y deseos) y problemas prácticos de los individuos, que reflejan las distintas posiciones en la sociedad" (Lindón, 2002, p. 34, cursivas en el original). Siguiendo a esta autora, a través de los modos de vida se puede acceder al proceso de construcción social del territorio. Este, en tanto 'espacio apropiado' (Raffestin, 2011), surge de la territorialización de los grupos sociales, de su búsqueda de dominar el espacio en términos político-económicos y de apropiárselo a nivel simbólico-cultural para asegurar su reproducción. Tal apropiación supone una "valorización simbólica de un grupo en relación con su espacio vivido" (Haesbaert, 2011, p. 35), valorización que puede reconstruirse mediante los modos de vida de los/las entrevistados/as, sus prácticas diarias, cuyos significados traslucen cómo el territorio en el que procuran reproducirse es producido en, por ejemplo, su acceso, control y uso de recursos.

En conclusión, esta investigación atenderá las reflexiones de los/las entrevistados/as sobre sus estrategias residenciales, los cambios y/o continuidades experimentados en sus modos de vida en materia laboral, familiar y de relaciones vecinales a partir de residir en Nueva Esperanza Este y el territorio que así construyen en el marco de programas habitacionales impulsados por los Estados nacional y provincial, cuyos principales rasgos se detallan a continuación.

\section{Pro.Cre.Ar y Mi Tierra, Mi Casa: el caso de Nueva Esperanza Este}

Diversas investigaciones (Cuenya, 2000; Barreto, 2012; Varela y Fernández Wagner, 2012) han dado testimonio de cómo, en Argentina, durante el transcurso de los siglos $\mathrm{XX}$ y XXI, los roles del Estado nacional y de los Estados provinciales fueron, en materia habitacional, redefiniéndose en el marco de distintos procesos políticos, económicos y sociales de orden multiescalar. El Estado nacional productor de conjuntos de viviendas 
colectivas 'llave en mano' para trabajadores asalariados conocido durante buena parte de la segunda mitad del siglo XX, dio paso a un Estado no solo 'facilitador' de la iniciativa privada sino, además, cedente de competencias a Estados provinciales y municipales, llamados a asumir un mayor protagonismo en el diseño e implementación de políticas habitacionales ${ }^{7}$. Desde 2003, el Estado nacional recuperó cierta holgura en la disposición de recursos fiscales que contribuyó a re-centralizar la toma de decisiones, redefiniendo las relaciones con las instancias estatales subnacionales, destacándose "el diseño y la ejecución de operatorias masivas destinadas a viabilizar el acceso al suelo y la vivienda para sectores de menores ingresos" (Canestraro, 2016, p. 58). Con estos antecedentes, buscando, en efecto, no solo paliar el déficit habitacional del país sino también estimular el empleo en un contexto de amesetamiento de la actividad económica, en el año 2012, fue lanzado el Pro.Cre.Ar. Para no redundar en aspectos ya analizados de este programa (Elinbaum y Barenboim, 2018; Rodríguez Daneri, 2014), en su modalidad original, el mismo ofreció líneas de crédito para: a) la construcción, ampliación y/o refacción de viviendas para familias con terreno propio; y b) para familias sin terreno, la adquisición de este y construcción de vivienda o compra de vivienda a estrenar ${ }^{8}$. La inscripción al programa estuvo abierta para toda la población (la cual fue agrupada según criterios de ingresos, composición del grupo familiar, radicación geográfica, entre otros).

Por su parte, el programa MTMC fue lanzado por el Estado de la provincia de Santa Fe en diciembre de 2012, habilitando "un conjunto de herramientas orientadas a garantizar el acceso a suelo urbanizado, lotes con infraestructura y servicios básicos, a diferentes sectores de la población santafesina" (Secretaría de Estado del Hábitat de la Provincia de Santa Fe, 2012, p. 1) carentes de vivienda propia. A este programa fue afectado el suelo urbano, suburbano y rural identificado de dominio público provincial y el de dominio privado captado a través de donación, compra, expropiación y/o gestión asociada de urbanización (Barenboim, 2018). En el caso de suelo de dominio comunal o municipal, el programa, en el marco de convenios de gestión asociada celebrados entre los Estados locales y el provincial, financió las obras de urbanización, respetando la normativa y los procesos y tendencias de crecimiento de cada localidad.

En la ciudad de Santa Fe, autoridades del Estado provincial y municipal celebraron en diciembre de 2012 el "Convenio de Gestión Asociada de Urbanizaciones de Interés Social" en virtud del cual se urbanizaron trescientos sesenta lotes (una superficie de trece hectáreas) en el área noreste de la ciudad (Figura 1), barrio Nueva Esperanza Este. Con un préstamo del Estado provincial, su par municipal procedió a realizar apertura de calles, desagües pluviales, cordón-cuneta, estabilizado granular, alumbrado público, forestación, red eléctrica de baja tensión y red de agua, destinando cien lotes a beneficiarios del Pro.Cre.Ar.

Nueva Esperanza Este es una urbanización relativamente reciente de una zona de borde o de integración urbano-rural, discontinuada del tejido urbano, en lo que décadas atrás era parte del cordón hortícola de la ciudad. Además de los beneficiarios Pro.Cre.Ar y MTMC (mayoritariamente llegados entre 2015 y 2016 y asentados en la superficie B de la Figura 2), en el barrio habita población (en buena parte pescadores y recolectores de

7 En esta dirección se inscribe la reforma y descentralización hacia los Estados provinciales de recursos del Fondo Nacional de la Vivienda (Fo.Na.Vi) producidas en 1995, que permitieron reorientar fondos "desde la producción de conjuntos masivos de viviendas al crédito individual para financiar la compra, construcción o mejoramiento de la vivienda" (Cuenya, 2000, s/n).

8 También contempló el acceso a la vivienda en desarrollos urbanísticos localizados en terrenos públicos. 
residuos reciclables) relocalizada en octubre de 2010 y en febrero de 2017 producto de

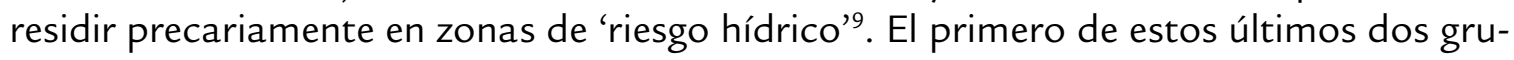
pos (veintidós familias) ocupó viviendas ${ }^{10}$ en el loteo realizado por el Estado municipal conocido como Los Quinchitos (superficie A de la Figura 2); al segundo (superficie C de la Figura 2) se le destinaron sesenta unidades construidas en el marco del Programa de Reconstrucción de la Ciudad ${ }^{11}$.

Ampliando lo expuesto, la Figura 3 muestra, por último, la tipología de viviendas construidas en el barrio.

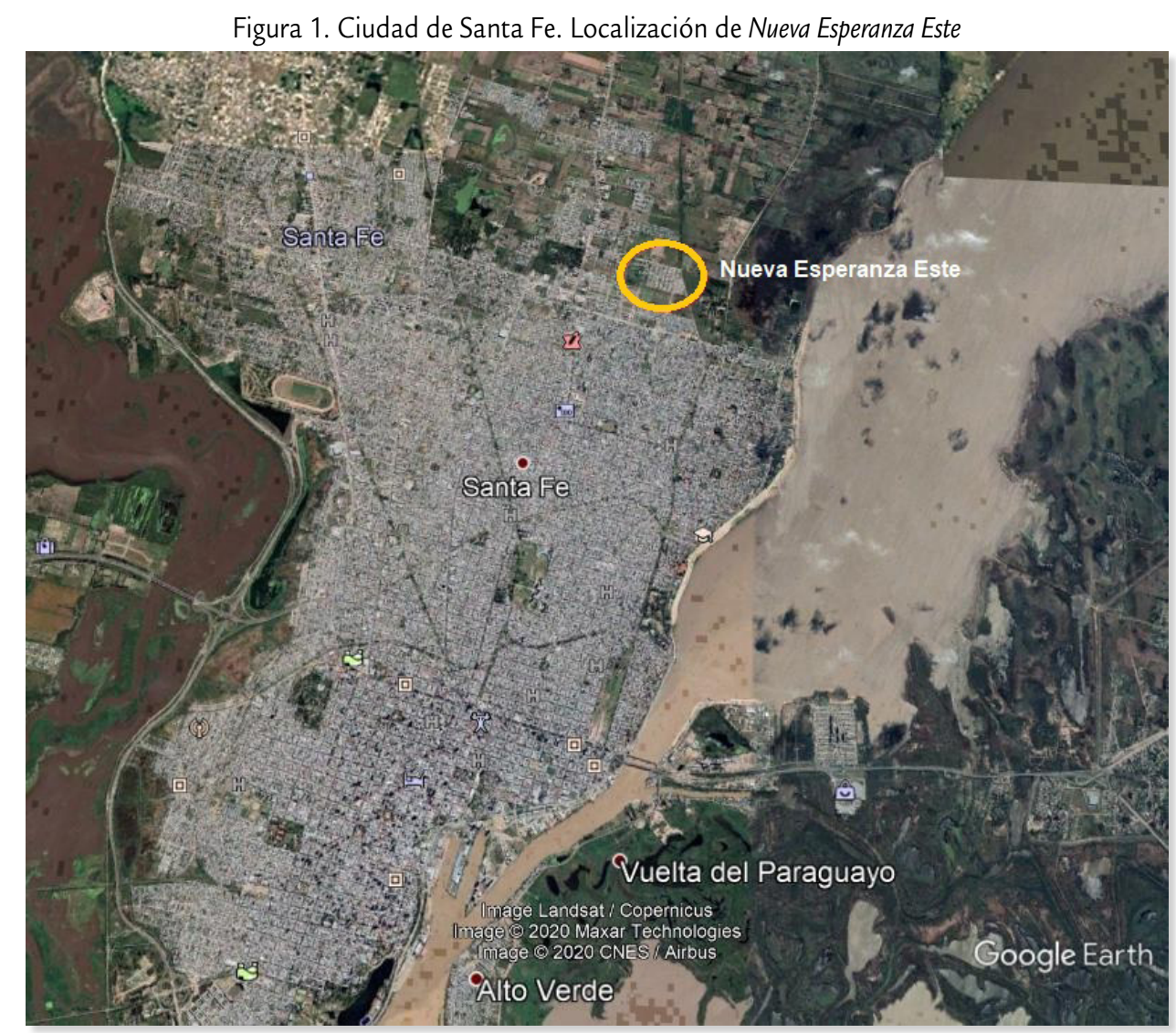

Fuente: Google Earth (30/01/2020)

9 Esta expresión alude a posibles inundaciones por desbordes de los ríos que circundan la ciudad (Salado hacia el oeste y Paraná -laguna Setúbal- hacia el este, los cuales confluyen en el sur). La última gran inundación que sufrió Santa Fe y algunas localidades aledañas ocurrió en 2003. Según fuentes periodísticas, hubo entonces veintitrés muertos y ciento treinta mil personas afectados por la crecida del río Salado (El Litoral, 29/04/2013).

10 Como el nombre del loteo alude (Los Quinchitos), se trató de módulos habitacionales de veinticuatro metros cuadrados en torno a una estructura de madera, techo de paja y paredes de fibra de cemento. Hacia 2012, debido a los persistentes reclamos de los moradores, el Estado municipal avanzó con el revestimiento externo de mampostería. Ese mismo año, a los veintidós primeros módulos construidos se sumaron doce viviendas sobre un total de veintiséis proyectadas (Municipalidad de la Ciudad de Santa Fe, 31/08/2012).

11 Programa financiado con Aportes del Tesoro Nacional girados desde 2016 al Estado municipal de Santa Fe, responsable de su formulación. Se construyó un total de doscientas viviendas (sesenta en Nueva Esperanza Este y ciento cuarenta en barrio Jesuitas) para hogares afectados por las recurrentes crecidas de los ríos Paraná y Salado (Municipalidad de la Ciudad de Santa Fe, 16/04/2016). 
Figura 2. Nueva Esperanza Este. Áreas según intervenciones habitacionales

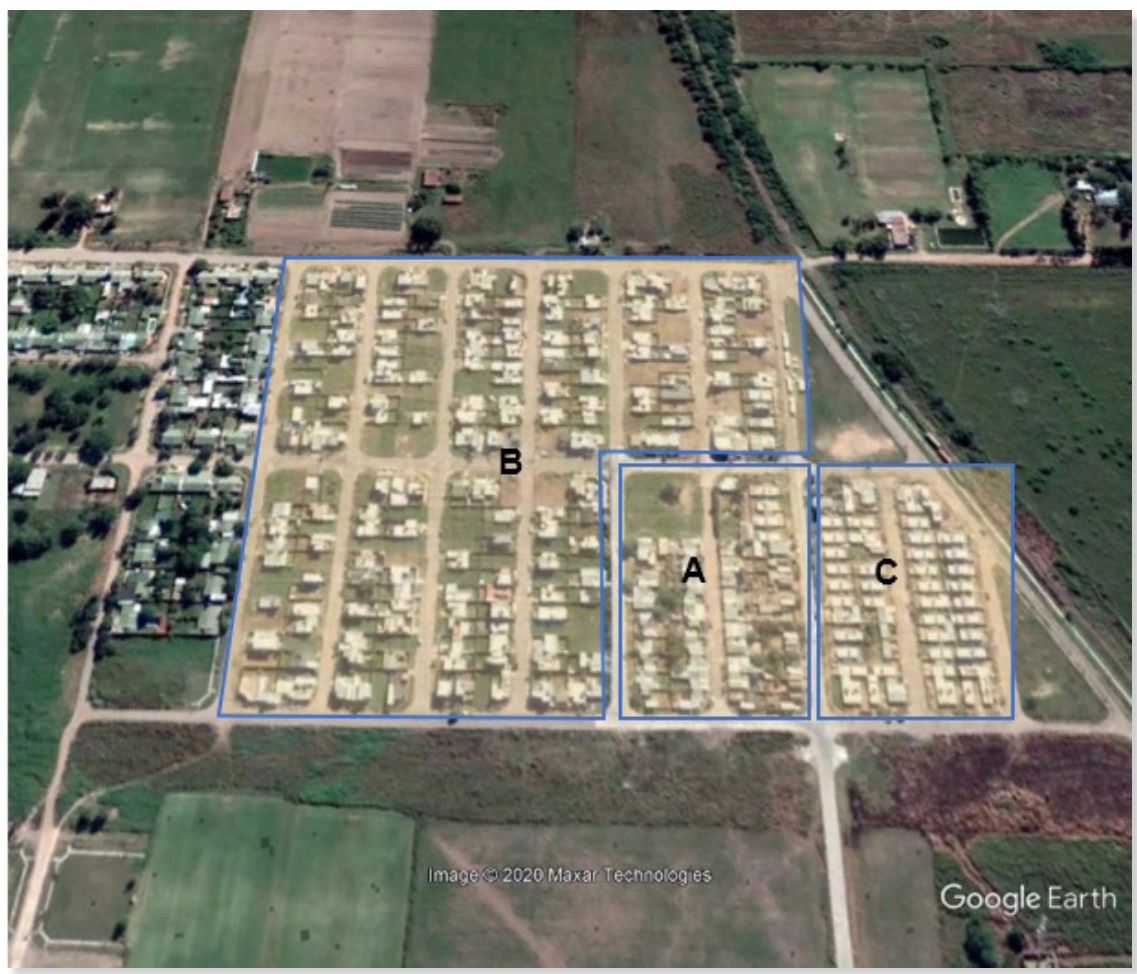

Referencias: A) primeras viviendas de la zona, conocidas como "quinchitos" (2010); B) viviendas enmarcadas en Pro.Cre.Ar (edificadas entre 2015-2016 aproximadamente); y C) viviendas correspondientes al Programa de Reconstrucción de la Ciudad (2016-2017)

Fuente: Google Earth (30/01/2020)

Figura 3. Tipología de viviendas construidas en Nueva Esperanza Este
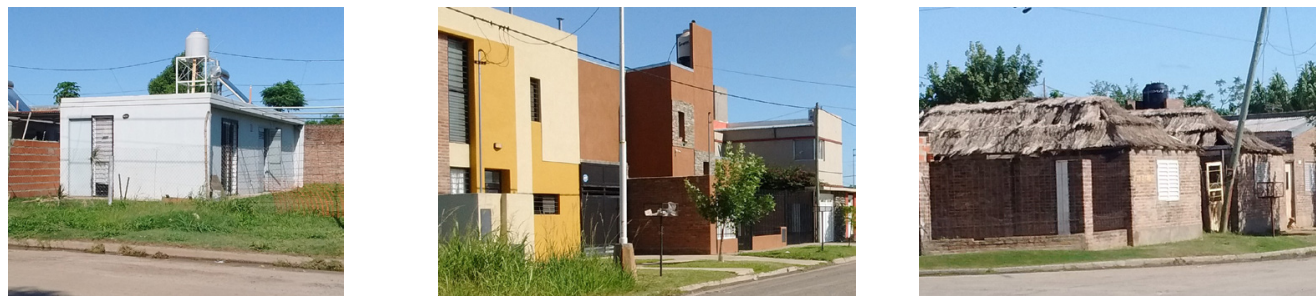

Referencias: A) vivienda construida con recursos del Programa de Reconstrucción de la Ciudad; B) viviendas construidas por beneficiarios Pro.Cre.Ar; y C) viviendas conocidas como "quinchitos" y que dieron el primer nombre al barrio

Fuente: imágenes tomadas por el autor (30/01/2020)

Nueva Esperanza Este limita, al este, con las ferrovías del Belgrano Cargas, seguidas del valle de inundación de la laguna Setúbal (distante a tres kilómetros). Hacia el norte y el oeste se encuentran lotes baldíos y barrios sindicales mientras que, al sur, separados por una mayor área, inicia el tejido urbano compacto e integrado. Tiene una función residencial y hacia septiembre de 2017 albergaba a tres mil personas aproximadamente (El Litoral, 27/09/2017). Recién en ese entonces comenzó a circular por el barrio la única línea de transporte de pasajeros que lo hace todavía hoy. Para acceder a otras líneas, hay que desplazarse diez cuadras. La plaza más cercana se ubica a seis cuadras (hay espacios 
verdes más próximos en los que se forman microbasurales) mientras que el centro de atención primaria de salud, los establecimientos educativos y los almacenes/supermercados y verdulerías más surtidos distan a algo más de diez cuadras. En este entorno viven los/las ocho jefes/as de hogar entrevistados/as, cuyos testimonios se pasa a analizar.

\section{PRESENTACIÓN Y ANÁLISIS DE LA EVIDENCIA}

\section{ESTRATEGIAS RESIDENCIALES}

Los cuatro entrevistados y las cuatro entrevistadas tienen -a enero de 2020- entre 33 y 44 años. Son, en su mayoría, profesionales que trabajan como asalariados (cuatro en el Estado) y cuentapropistas (o las dos cosas en simultáneo). De las cuatro mujeres entrevistadas, tres viven solas y de estas, una tiene un hijo. El resto vive en pareja y, con excepción de un caso, tiene hijos ${ }^{12}$.

Para todos y todas, Pro.Cre.Ar y MTMC representaron un salto disruptivo en sus trayectorias residenciales. Al momento de postular a dichos programas, el régimen de tenencia de vivienda de siete de ellos/as era el alquiler (solo un entrevistado residía en la vivienda de sus padres). En los testimonios recogidos, este modo de ocupación tiene connotaciones negativas; antes que verlo como un gesto asociado a la movilidad y a la autonomía (descohabitar durante la juventud, residir en la ciudad procediendo de zonas rurales), se lo referencia como una 'presión'. "Cada dos años otra vez, no sabés con qué te vas a encontrar, salir a pedir a familiares o amigos que de nuevo te salgan de garantes" (entrevistada D); "pedir un préstamo para poder pagar" (entrevistada A); los gastos asociados al contrato de alquiler (honorarios de agentes inmobiliarios, sellados, etcétera), ilustran al respecto. Alquilar es "tirar plata a una bolsa vacía" (entrevistado E) en tanto el inquilino no capitaliza el dinero erogado. Reflejando la idea de que la trayectoria residencial es una suerte de carrera cuyo arribo es la propiedad de la vivienda, alquilar se asocia con "no avanzar", con un "permanecer estancado" (entrevistada B). Los pocos comentarios positivos ligados al inquilinato pasan por la localización del inmueble rentado en términos de disponibilidad de servicios y proximidad al lugar de trabajo, a centros comerciales o a las redes de familiares y amigos.

Por el contrario, ser dueño/a de la vivienda es cumplir un anhelo generalmente representado como de difícil concreción dados sus precios de mercado, los niveles de ingresos acreditables, las restricciones al crédito hipotecario o la ausencia de herencias.

La gente de mi edad que tenía una casa era porque la heredó o porque le regalaron un terreno y empezó de a poquito a construir. Pero no existía en mi generación el crédito hipotecario (...) Cuando salimos sorteados... ni siquiera me planteé la posibilidad de preguntarme ¿me gusta o no me gusta? Era la única posibilidad que tenía. (entrevistada D)

12 Ampliando la caracterización de las y los informantes (a quienes se identifica con una letra asignada por orden de abecedario para preservar su anonimato); A tiene 43 años y es asalariada del sector público. No tiene hijos/as, vive sola y previamente alquilaba una vivienda en la zona norte del macrocentro de la ciudad. Del conjunto de informantes, es la única que no posee automóvil ni motocicleta. B, de 38 años, tiene dos empleos asalariados (uno en el sector público y otro en el sector privado). Sin hijos/as, vive sola y con anterioridad alquilaba vivienda en un barrio consolidado del sur de Santa Fe. C, de 42 años, trabaja como cuentapropista. Vive con su pareja e hijo y procede de un barrio consolidado del oeste del macrocentro santafesino. D, tiene 42 años y es empleada del sector público. Vive con su hijo y antes de residir en Nueva Esperanza Este alquilaba en la zona céntrica de la ciudad. E, de 44 años, es comerciante (empleador) en la zona norte del macrocentro. Vive con su pareja y dos hijas. Previamente rentaba un departamento en cercanías de su local comercial. F, de 34 años, es asalariado del sector privado. Vive con su pareja e hijo. Procede de un barrio consolidado de la zona norte de Santa Fe. G tiene 43 años. Trabaja como cuentapropista. Vive con su pareja y dos hijos/as. Antes de su traslado a Nueva Esperanza Este alquilaba una vivienda en un barrio consolidado del noreste de la ciudad. $\mathrm{H}$, de 33 años, es cuentapropista y tiene además una beca para realizar estudios de posgrado. Vive con su pareja, no tiene hijos/as y previamente vivía con sus padres en la zona centro de Santa Fe. 
Tanto para quienes provienen de familias inquilinas como de familias propietarias, la titularización de la vivienda es una suerte de imperativo siempre presente en el horizonte de prácticas residenciales.

La vivienda poseída es, en oportunidades, menos pensada en términos de 'casa'13 que en términos de un capital que confiere seguridad y protección ante la vejez, la posibilidad de mudarse y alquilar en otra zona de la ciudad, asegurar una herencia para sucesores y que amplía la "estructura de oportunidades"14: "tener una vivienda te hace cambiar tu camino (...) Te cambia lo que vos querés a futuro (...) Poder tener y proyectarse" (entrevistada A). Es una tenencia que, en este sentido, habilita viajar, estudiar, iniciar actividades recreativas, tomando cierta distancia de las necesidades materiales inmediatas.

La segunda variable de análisis de las estrategias residenciales remite a la preferencia por viviendas individuales o por departamentos. Las viviendas construidas por los hogares analizados corresponden al primer tipo. Esto se explica no en términos de estrategia sino por el hecho de que en los cien lotes producidos en el marco de MTMC que el Estado municipal vendió a sorteados del Pro.Cre.Ar, solo estuvo permitido construir esa clase de unidad habitacional. De ellas se valora, por un lado, la "independencia", no compartir palieres o ingresos, evitar la proximidad de vecinos "molestos" (entrevistado G) $y$, por otro, el "espacio" que confieren, significante que designa nuevas formas de habitar por el hecho de contar con patio, cochera, vegetación e incluso mascotas. Este "espacio" es destacado para la crianza de hijos e hijas frente al "encierro" (entrevistado E) y las precauciones propias del centro de la ciudad.

Si bien la posibilidad de construir -en un marco de recursos acotados- permitió proyectar en la edificación gustos y preferencias (algo que el arrendamiento generalmente no permite), distintos testimonios coinciden en que, por momentos, la ejecución de la obra se volvió un "peso" y que hubo que aprender a convivir con la distancia entre lo imaginado y lo edificado: losas rajadas, filtraciones de humedad, aberturas fuera de escuadra. "Empecé a sentir que estaba más liviana cuando alquilaba, porque yo iba, pagaba un alquiler a fin de mes y me desentendía de todos los problemas" (entrevistada B).

La localización de la vivienda es, finalmente, la última variable que hace al análisis de las estrategias residenciales. El Estado local fue quien determinó la localización del suelo a urbanizar con fondos prestados por el Estado provincial, motivo por el cual los márgenes de decisión en este plano fueron estrechos para los hogares si es que querían construir con el crédito del Pro.Cre.Ar. Antes de que el Estado local anunciara la venta de cien lotes, la escasez de suelo servido y los altos precios de mercado de por entonces llevó a que muchos hogares buscaran terrenos no solo en Santa Fe sino en algunas localidades contiguas que hacen a su área metropolitana. Nueva Esperanza Este, aún en la periferia norte, se presentaba como un barrio 'en' la ciudad y a un precio accesible ${ }^{15}$,

13 El término 'casa' tiene una carga afectiva. Ella "es un espacio íntimo de alto contenido simbólico, condensador de sentidos y también es un espacio básico que ubica al ser humano de una manera particular en el mundo" (Lindón, 2005, s/n). 'Vivienda', en cambio, tiene una connotación más técnica que alude a los aspectos materiales de la construcción.

14 La categoría refiere a "las probabilidades de acceso a bienes, a servicios o al desempeño de actividades. Estas oportunidades inciden sobre el bienestar de los hogares ya sea porque permiten o facilitan a los miembros del hogar el uso de sus propios recursos o porque les proveen recursos nuevos. El término 'estructura' alude al hecho de que las rutas al bienestar están estrechamente vinculadas entre sí, de modo que el acceso a determinados bienes, servicios o actividades provee recursos que facilitan a su vez el acceso a otras oportunidades" (Katzman, 1999, p. 21).

15 Según lo informado por los entrevistados y las entrevistadas, el precio que el Estado local fijó por cada uno de los cien lotes (de doscientos metros cuadrados) puestos en venta a beneficiarios Pro.Cre. Ar, fue de diez mil dólares, 
particularmente para quienes no tenían ahorros. De todos modos, la evidencia del caso indica que dónde se localiza la vivienda, es una cuestión absolutamente subordinada a la posibilidad de acceder a su propiedad: "el estar allá (zona céntrica) era mucho mejor pero no era nuestro" (entrevistado E); "era irme como a la nada, porque era la nada en ese momento (el loteo). Pero dije bueno, no tengo otra chance, no puedo dejar pasar la posibilidad de ser propietaria" (entrevistada D); "va a ser nuestro (...) Lo otro lo vas acomodando" (entrevistado E). Prima la decisión de asegurar la propiedad de la vivienda y luego se construyen los argumentos que refuerzan dicha decisión. En esta dirección, varios testimonios apuntan que el barrio "se urbanizará más" (entrevistado G) a futuro, elevando el valor del inmueble. Algunos informantes ( $A, B, E, F$ y G) destacan el hecho de haber vivido en algún momento de sus vidas en las zonas norte y noreste de la ciudad -factor que les confería algún conocimiento y/o vinculación con el entorno- y solo dos informantes ( $\mathrm{B}$ y E) mencionan la residencia cercana (quince-veinte cuadras) de familiares.

\section{LOS MODOS DE VIDA}

Como se dijo, estas decisiones residenciales conllevan cambios en los modos de vida de los hogares que se manifiestan en relación con el trabajo, la familia y el vecindario. Con respecto a los dos primeros, dado el alejamiento de las centralidades urbanas, los medios de transporte toman una relevancia clave en la cotidianeidad de los hogares. Para quienes no disponen de automóvil o motocicleta, que la línea de transporte público de pasajeros que llega al barrio cumpla frecuencias, horarios, paradas y recorridos establecidos, es central. Del otro lado, quienes dependen menos del transporte público, dependen más de sus propios vehículos. Esto, por un lado, confiere una libertad de acción más costosa: "tengo un problema con el vehículo porque el consumo de combustible es muy grande por el hecho de ir y venir muchas veces al centro (de la ciudad)" (entrevistado G) y, por otro, implica "una forma diferente de vincularte con el espacio público" (entrevistada D): perder hábitos de caminar, la tensión del tráfico, relegar el disfrute del patrimonio paisajístico en función del desplazarse, hechos vividos con pesar y/o fatiga por quienes coinciden en estas experiencias. A su vez, la ausencia de despensas o supermercados cercanos obliga a los hogares a realizar buena parte de sus compras fuera del barrio por lo que, con o sin movilidad, se vuelve una actividad que supone cierta previsión, cálculo y cuidado por no olvidar bienes indispensables (garrafas de gas, por ejemplo).

En algunos casos, la organización hogareña en la nueva localización ha desencadenado incluso cambios laborales: entrevistados/as con una ocupación asalariada y otra cuentapropista, optaron por resignar la primera y "trabajar freelance en la vivienda" (entrevistada C), priorizando además tareas domésticas del cuidado. Otros/as han aprovechado la posibilidad de conseguir una ocupación más cercana al domicilio.

Varios padres y madres optaron por inscribir a sus hijos e hijas en colegios y clubes deportivos más cercanos, para así evitar los largos desplazamientos. Quienes no incurrieron en estos cambios mencionan que lidian con el "ir y venir" y "le buscan la vuelta" (entrevistado G) deteniéndose en casas de familiares para trabajar o hacer tiempo entre actividades laborales.

El nuevo modo de vida también ha ocasionado conflictos de pareja: "la distancia nos genera efectos colaterales. Peleas, tipo 'llevala vos. No, llevala vos. Pero te toca a vos, yo tengo orga-

tope que este programa permitía asignar del total del dinero asignado a la compra de terreno. 
nizado el fútbol...' " (entrevistado E) y la pérdida de algunas costumbres que "se extrañan" tales como asistir a eventos deportivos, practicar deportes o reunirse más frecuentemente con familiares, por ejemplo.

En el plano del vecindario, si bien no todos/as se interesan por participar de la "vida del barrio", los testimonios tienden a resaltar la conformación de un "grupo de buena gente" (entrevistada A), integrado por personas de edades similares, que mantienen vínculos estrechos (aceitados por el uso de WhatsApp), con reuniones regulares. Estos nuevos lazos compensan parcialmente los antiguos grupos de amigos, de compañeros de trabajo o de deportes, ahora resentidos por el distanciamiento: "tenemos el grupito de la peña, el grupito de la manzana, que, también te los vas haciendo porque te quedaste lejos de los otros grupos" (entrevistado E). Conviene aclarar que esta "buena gente" refiere estrictamente a beneficiarios Pro.Cre.Ar y excluye a vecinos de Los Quinchitos y a los relocalizados llegados en 2017 en el marco del Programa de Reconstrucción de la Ciudad. De estos dos grupos, los primeros son concebidos como legítimos habitantes del barrio por haber llegado antes, mientras que los segundos son "reubicados", es "la gente de atrás" (entrevistado G). Con matices, ambos son connotados negativamente en sus hábitos laborales, de consumo de alcohol, de cuidado de espacios públicos, sospechados de ser los "choros" que roban en las viviendas de quienes quieren "avanzar a fuerza de trabajo" (entrevistada A). Si bien el Estado local, en un primer momento, había previsto que las viviendas enmarcadas en el Programa de Reconstrucción de la Ciudad se construyan de manera intercalada con las de los beneficiarios Pro.Cre.Ar -apostando que ello contribuiría a la integración física y social del barrio (El Litoral, 30/06/2016)- el rechazo de estos últimos condujo a que las sesenta viviendas financiadas por el Estado nacional se concentraran en dos manzanas en los márgenes del barrio, frente a las vías del ferrocarril:

\footnotetext{
La lucha madre era acá no los queremos. Me vas a poner un cartonero al lado que, lo siento mucho, es su actividad, todo bien, pero yo invertí más de dos millones de pesos en mi casa, no solo los quinientos mil pesos que me dio Pro. Cre.Ar. El precio del barrio va a bajar. Yo no soy ni gorila ni nada, pero no quiero convivir todo el día con la música al palo, con choros. (entrevistado E)
}

Esta mirada, aunque compartida en términos generales por los/las entrevistados/ as, se complejiza en algunos casos con argumentaciones que buscan matizar y contextualizar la situación:

Hay barrios que están muy pegaditos al nuestro, porque siguen siendo del mismo barrio, donde la realidad social es muy distinta, donde hay mucha pobreza. Es un gran contraste: en una cuadra, ves una casa de Los Quinchitos (cuyos residentes) viven de la clasificación de basura y de criar animales y en la otra esquina tenés una casa de dos pisos, con dos o tres autos... Eso también incide en el tema de seguridad. Cuanta más exclusión hay, más inseguridad puede haber. (entrevistada A)

Esa "inseguridad" es un tema omnipresente en la cotidianeidad de los y las informantes: "hace días entraron y tuvieron de rehén a una familia, a media cuadra de casa" (entrevistada A); "hace dos días rompieron la ventana de una casa y la desvalijaron" (entrevistado F); "con esto que me pasó del robo, estoy un poco susceptible" (entrevistada B). Está instalado desde que se comenzaron a edificar las primeras viviendas. Explica que los vecinos paguen a vigilantes ad hoc y dispongan para ellos una pequeña casilla/garita, "manera de resguardar un poco la seguridad del barrio (que) empezó cuando se estaban haciendo las obras... Había muchísimas casas en obra y se robaba" (entrevistada D), explica también la permanente preocupación por rejas y tapiales: "más alivio nos dio cuando el (vecino) de atrás empezó a construir y lo primero que hizo fue la reja del frente" (entrevistado F) e incluso, para algunos/as, condiciona hábitos y ho- 
rarios de circulación callejera: "para irnos a caminar a un lugar donde no corras riesgo, tenemos que irnos sí o sí a la costanera" (entrevistado E); "calculo salir del trabajo y llegar a mi casa después de las 16, para que sea seguro" (entrevistada A).

Estos modos de vida repasados 'hablan' del tipo de territorio que se va construyendo, cuestión abordada en el siguiente -y último- apartado.

\section{CONSIDERACIONES FINALES: LA CONSTRUCCIÓN DE UN TERRITORIO 'INAPROPIADO’}

$\mathrm{Si}$, como se dijo antes, el territorio es el espacio que un grupo social -buscando su reproducción- apropia en su acceso, control y uso, los modos de vida recién descriptos configuran uno todavía 'inapropiado', en el sentido de que la apropiación lograda por los hogares es parcial. Las marcas que dan cuenta de tal apropiación prácticamente se reducen a la vivienda, al ámbito privado, sin que se las encuentre en parques, calles o comercios. Así lo expresan algunas entrevistadas, por ejemplo, ligadas al territorio solo a través de la "casa", por necesidad o búsqueda de capitalización, sintiendo que no pertenecen a él y que él no les pertenece: "estoy acá pero no soy de acá. Estoy acá circunstancialmente"; "no es que llego al barrio. Llego a mi casa (...) En mi casa está todo muy para adentro" (entrevistada D). Un territorio virtualmente híper comunicado por WhatsApp, pero en el que los intercambios directos, cara a cara con el vecindario son reducidos: "llego a mi casa, me meto adentro... de hecho, mi casa está toda tapiada. No veo hacia afuera" (entrevistada A); "no sé hasta qué punto me interesa vincularme, interiorizarme, participar" (entrevistada D).

Para otros -suerte de 'pioneros' a la hora de construir la vivienda-, se trata de un territorio investido con valores tanto afectivos (siempre entre beneficiarios Pro.Cre.Ar) como económicos. De similares rasgos socioeconómicos y con hijos en el hogar, las custodias realizadas durante la etapa de construcción para evitar robo de materiales o los reclamos ante el Estado local por la prestación de servicios, cimentaron amistades que fungen como activo al relevar parcialmente vínculos previos algo afectados por el distanciamiento. "Al barrio, como lo formamos de cero, lo tenemos como muy propio" (entrevistado G). Además, el territorio es también representado como un recurso económico a preservar e incrementar; de allí los recaudos y las acciones desplegadas para evitar determinado tipo de vecindades indeseadas.

Sin embargo, en ambos casos, el territorio no está plenamente apropiado debido a la 'inseguridad' que se manifiesta. Construcción de altos muros y portones, organización de un servicio de vigilancia barrial, desplazamientos hacia espacios públicos distantes para actividades de ocio, ajustes en horarios y calles de circulación por el barrio, hacen a un territorio de uso incompleto, en el que incluso dicha dimensión de recurso económico se desdibuja por el miedo y las constantes precauciones que los hogares deben tomar. Estos vinculan dicha inseguridad con la presencia de un grupo social que cohabita el territorio y que, percibido como portador de pautas sociales, económicas y culturales diferentes ("la gente de atrás", los "reubicados"), opera como una otredad que amenaza la reproducción de la vida que un grupo busca al territorializarse.

De esa otredad imprevisible, que no se puede controlar, se busca distanciarse evitando los contactos: "en los módulos nuevos que hicieron (viviendas del Programa de Reconstrucción de la Ciudad) no me meto" (entrevistado G) y delimitando fronteras "una de las salidas del barrio es por calle Sarmiento, donde están Los Quinchitos. Siempre hay mucha basura, entonces a determinada hora uno no quiere transitar por ahi" (entrevistado $\mathrm{H}$ ). 
En términos de Lefebvre (1991) y Haesbaert (2009), Nueva Esperanza Este sería un territorio que, en tanto 'espacio vivido' a través de imágenes y memorias de los/las informantes, paradójicamente conjugaría visiones de un barrio que supone rejas, delincuencia y largos desplazamientos diarios, imágenes ligadas al miedo, la 'inseguridad' y al esfuerzo cotidiano, con aquellas de vivienda propia, anhelo de progreso y ascenso social, vinculadas a la construcción de un porvenir más 'seguro', menos incierto. En tanto 'espacio percibido', espacio practicado, los usos que los habitantes hacen de las calles y plazas del barrio -y que darían a este su carácter social- se limitan, como se apuntó, a la circulación en automóvil, motocicleta o transporte público para acceder a la vivienda o salir de ella, sin que hubiera referencias a prácticas deportivas y/o de esparcimiento en clubes y/o parques cercanos. Finalmente, como 'espacio concebido' por autoridades estatales para la integración de diferentes grupos sociales (relocalizados y beneficiarios Pro.Cre.Ar), Nueva Esperanza Este es un ejemplo de cómo algunos de tales grupos buscan reproducirse tomando distancia de otros, distancia que, si no puede ser física, convoca al desarrollo de estrategias a través de las cuales evitar los intercambios vecinales (Lindón, 2002): excluir calles por donde desplazarse, minimizar el uso espacios públicos, emplear (de ser posible) movilidad propia antes que transporte urbano de pasajeros.

El análisis hasta aquí realizado ha buscado complejizar las miradas que ven en los procesos de expansión horizontal urbana la ampliación de espacios de exclusión de población pauperizada o el gesto de grupos acomodados que buscan tomar distancia física en barrios cerrados. Para ello, considerando el punto de vista de los propios actores, se han analizado las estrategias residenciales, los modos de vida y el tipo de territorio que construyen hogares de sectores medios alcanzados por programas habitacionales estatales. Además de lo expuesto en el inicio de este apartado, la tarea ha permitido echar luz sobre algunos fenómenos que ameritan ser destacados. Uno de ellos refiere a cómo el Estado, con sus intervenciones, contribuye a que los hogares observados se aparten de los 'destinos probables' del grupo social al que pertenecen (Bonvalet y Dureau, 2002). En efecto, en ausencia de Pro.Cre.Ar o MTMC, numerosos hogares seguirían, ceteris paribus, en condición de inquilinos, con la imprevisibilidad que se le asocia. Por último, es de resaltar la disposición a realizar cambios profundos por parte de los hogares cuando esos cambios se vinculan con el acceso a la propiedad de la vivienda: tiempos y costos de desplazamiento, lazos familiares y de amistad, hábitos recreativos y/o de consumo e incluso la inserción laboral se ajustan a las condiciones que ofrece la localización de aquella.

\section{REFERENCIAS}

Barenboim, C. (2018). Análisis del programa de urbanización "Mi tierra, mi casa" en la ciudad de Rosario. X Seminario Internacional de Investigación en Urbanismo. Barcelona, 14 y 15 de junio. Recuperado de https://rdu.unc.edu.ar/bitstream/handle/11086/6338/An\%C3\%A1 lisis\%20del\%20programa\%20de\%20urbanizaci\%C3\%B3n\%20Mi\%20tierra\%2c\%20 mi\%20casa.pdf?sequence=45\&isAllowed=y (consulta 17 de diciembre de 2019).

Barreto, M.Á. (2012). Cambios y continuidades en la política de vivienda argentina (20032007). Cuadernos de Vivienda y Urbanismo, 5(9), 12-30.

Bonvalet, C. y Dureau, F. (2002). Los modos de habitar: decisiones condicionadas (pp. 69-87). En F. Dureau, V. Dupont, E. Lelièvre, J.P. Lévy y T. Lulle (Coords.) Metrópolis en 
movimiento: una comparación internacional. Bogotá: Alfaomega.

Canestraro, M. L. (2016). Sobre el derecho a la ciudad y el acceso al suelo urbano. Reflexiones a partir de intervenciones estatales recientes (Mar del Plata, 2012-2015). Estudios Socioterritoriales. Revista de Geografía, (20), 57-74.

Cuenya, B. (2000). Cambios, logros y conflictos en la política de vivienda en Argentina hacia fines del siglo XX. Boletín CF+S, 29/30. Recuperado de http://habitat.aq.upm.es/ boletin/n29/abcue.html (consulta 05 de diciembre de 2019).

Dematteis, G. (1998). Suburbanización y periurbanización. Ciudades anglosajonas y ciudades latinas (pp. 17-33). En J. Monclús (Ed.) La ciudad dispersa. Barcelona: Centro de Cultura Contemporània de Barcelona.

Di Virgilio, M.M. y Gil y de Anso, M.L. (2012). Estrategias habitacionales de familias de sectores populares y medios residentes en el área metropolitana de Buenos Aires (Argentina). Revista de Estudios Sociales, 44, 158-170.

Elinbaum, P. y Barenboim, C. (2018). Efectos metropolitanos de una política de vivienda mixta. El caso del ProCreAr. Cuadernos de Vivienda y Urbanismo, 11(21), 1-20.

Elorza, A. (2019). Segregación residencial y estigmatización territorial. Representaciones y prácticas de los habitantes de territorios segregados. EURE, 45(135), 91-109.

Gutiérrez, A. (1995). Estrategia habitacional, familia y organización doméstica. Cuadernos de Antropología Social, 10, 151-165.

Haesbaert, R. (2009). Dilema de conceitos: espaço-território e contenção territorial (pp. 95-120). En M. Saquet y E. Sposito (Orgs.) Territórios e territorialidades: teorías, processos e conflitos. São Paulo: Expressão Popular.

Haesbaert, R. (2011). El mito de la desterritorialización: del "fin de los territorios" a la multiterritorialidad. Siglo XXI: México.

Katzman, R. (1999). Activos y estructuras de oportunidades. Estudio sobre las raíces de la vulnerabilidad social en Uruguay. Montevideo: CEPAL - PNUD.

Lefebvre, H. (1991). The Production of Space. Oxford: Blackwell.

Lindón, A. (2002). La construcción social del territorio y los modos de vida en la periferia metropolitana. Territorios, 7, 27-41.

Lindón, A. (2005). El mito de la casa propia y las formas de habitar. Scripta Nova, 194(20). Recuperado de http://www.ub.edu/geocrit/sn/sn-194-20.htm (consulta 18 de enero de 2020).

Marradi, A.; Archenti, N. y Piovani, J.I. (2007). Metodología de las ciencias sociales. Buenos Aires: Emecé Editores.

Municipalidad de la Ciudad de Santa Fe y Bolsa de Comercio de Santa Fe. (2013). Santa Fe. Cómo vamos 2012. Santa Fe: Municipalidad de la Ciudad de Santa Fe y Bolsa de Comercio de Santa Fe.

Pírez, P. (con la colaboración de Cosacov, N.). (2016). El derecho a la ciudad y la reestructuración neoliberal en Buenos Aires: movilizaciones de sectores populares ("insolventes") y clases medias ("solventes"): ¿Una extensión conceptual? Seminario Construcción de Ciudadanía y Nuevos Actores en las Grandes Ciudades. México: Centro de Investigaciones Interdisciplinarias en Ciencias y Humanidades-UNAM.

Raffestin, C. (2011). Por una geografía del poder. Michoacán: El Colegio de Michoacán.

Ribeiro, L.C.Q. (2007). Metrópolis brasileñas: ¿cómo gobernar la urbs sin civitas? Nueva Sociedad, 212, 97-111. 
Rodríguez, M.C.; Di Virgilio, M.M.; Arqueros Mejica, S.; Rodríguez, M.F. y Zapata, M.C. (2015). Contradiciendo la Constitución de la ciudad. Un análisis de los programas habitacionales en la ciudad de Buenos Aires en el período 2003-2013. Documentos de Trabajo, 72. Buenos Aires: Instituto de Investigaciones Gino Germani, Facultad de Ciencias Sociales, Universidad de Buenos Aires.

Rodríguez Daneri, M.E. (2014). Crecimiento urbano y acceso al suelo: implicaciones del programa Crédito Argentino del Bicentenario en La Plata. XI Simposio de la Asociación Internacional de Planificación Urbana y Ambiente. La Plata, 16-19 de septiembre. Recuperado de http://sedici.unlp.edu.ar/bitstream/handle/10915/55093/Documento_completo. pdf-PDFA.pdf?sequence=1 (consulta 25 de enero de 2020).

Varela, O. y Fernández Wagner, R. (2012). El retorno del Estado. Los Programas Federales de Vivienda en el AMBA (pp. 16-41). En C. Cravino (Org.) Construyendo barrios: transformaciones socioterritoriales a partir de los Programas Federales de Vivienda en el Área Metropolitana de Buenos Aires (2004-2009). Los Polvorines: UNGS.

\section{OTRAS FUENTES}

El Litoral (29/04/2013). Se cerró la brecha, pero no la herida. Recuperado de https://www. ellitoral.com/index.php/diarios/2013/04/29/metropolitanas/AREA-07.html?otras_interior (consulta 15 de enero de 2020).

El Litoral (30/06/2016). Nueva Esperanza Este y el desafío de integrar realidades sociales dispares. Recuperado de https://www.ellitoral.com/index.php/diarios/2016/06/30/metropolitanas/AREA-01.html (consulta 21 de enero de 2020).

El Litoral (27/09/2017). La línea 8 extendió su recorrido hasta Nueva Esperanza Este. Recuperado de https://www.ellitoral.com/index.php/diarios/2017/09/27/metropolitanas/ AREA-02.html (consulta 15 de enero de 2020).

Municipalidad de la Ciudad de Santa Fe (31/08/2012). Nueva Esperanza Este: el Municipio avanza en la ampliación y construcción de viviendas. Recuperado de https://www.santafeciudad.gov.ar/nueva_esperanza_este_municipio_avanza_ampliacion_construccion_viviendas/ (consulta 13 de abril de 2020).

Municipalidad de la Ciudad de Santa Fe (16/04/2016). Emergencia hídrica: el presidente Macri ratificó obras para Santa Fe. Recuperado de https://www.santafeciudad.gov.ar/emergencia_ hidrica_presidente_macri_ratifico_obras_para_santa/ (consulta 13 de abril de 2020).

Secretaría de Estado del Hábitat de la Provincia de Santa Fe (2012). Resolución No 153. Creación programa Mi Tierra, Mi Casa. Recuperado de https://www.santafe.gov.ar/index.php/ web/content/download/192665/940378/file/Resoluci\%C3\%B3n\%20153\%20Mi\%20Tierra,\%20Mi\%20Casa.pdf (consulta 17 de diciembre de 2019).

Martín Carné es Doctor en Ciencia Política. Investigador Asistente del Consejo Nacional de Investigaciones Científicas y Técnicas (CONICET). Es docente de la Universidad Nacional del Litoral y de la Universidad Nacional de Rosario. Sus temas de investigación refieren a políticas públicas de producción de suelo urbano y a dispositivos institucionales de gestión de áreas metropolitanas. Instituto de Humanidades y Ciencias Sociales del Litoral. Universidad Nacional del Litoral (UNL-CONICET). Ciudad Universitaria. Paraje El Pozo, (3000) Ciudad de Santa Fe, Santa Fe, Argentina, carnetes@hotmail.com, ORCID https://orcid.org/0000-0003-2386-324X 